\title{
Big Data And The Hobson's Choice For IT Management
}

Mohammad Dadashzadeh, Oakland University, USA

\begin{abstract}
The advent of Big Data is confronting Chief Information Officers (CIOs) with the fundamental dilemma of what role do we want Information Technology (IT) to play in building the DSS (Decision Support Systems) portfolio for the enterprise? This paper points out that the question is an existential one. For too long IT Management has concentrated on becoming the principal source of support for managers, in all functional areas and at all managerial levels, with the information they require for their control needs. At the same time, the IT function has been content to play second fiddle to domain experts, knowledge engineers, and decision modelers from outside the IT function for the same mangers' needs for problem solving, planning, and decision making. Big Data, with its real-time impact on managerial control and planning needs, changes this status quo. It behooves CIOs to confront this Hobson's choice lest another C-level officer role such as Chief Analytics (or Data Science) Officer diminish the place of the IT function and the chant of does IT matter reverberate once again.
\end{abstract}

Keywords: Management Information Systems; MIS; Big Data; Key Performance Indicator; KPI; Decision Support Systems; DSS; Managerial Planning and Control; Data Science; Business Analytics; IT Planning and Strategy

\section{INTRODUCTION}

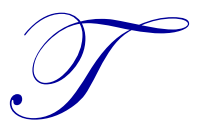

he annals of the relatively young Management Information Systems (MIS) field are replete with technology waves and management innovations that have left their mark not only on the way the MIS function in organizations operate, but also on the acronyms and abbreviations that have become a part of our common language. Some technology waves like PC, WWW, ERP, CRM, SaaS, and BI have been big enough to spawn entire new industries and companies that have changed the world (McNamee and Maples, 2011). Similarly, some management innovations like IRM (Information Resource Management), BPR (Business Process Reengineering), and EA (Enterprise Architecture) have demonstrated a level of acceptance that they have become interwoven to the fabric of the MIS mission for information management and delivery. Lest we forget, the MIS field has also had its share of exciting system abbreviations and inflated expectations such as OAS (Office Automation Systems), KWS (Knowledge Work Systems), EIS (Executive Information Systems), ESS (Executive Support Systems), IOS (Inter-Organizational Systems), and KMS (Knowledge Management Systems).

Going back to its etymological roots, MIS is intended to refer to a system that provides management with the information they need to manage. In turn, management is about planning and control (and the implied accountability) to achieve key objectives. Therefore, the role of MIS is to support management, at all levels of managerial hierarchy and in all functional areas of the organization, with the information they need for planning and control. Given key performance indicators, it is simple to infer that for each manager the right information is what allows her to take the pulse of her performance measures and the right support when a goal is not being met is to help determine the root cause of the problem and to help design, plan, and implement changes to get back on course. Whether an organization's MIS is automated or manual it must consist of the following three subsystems:

1. Transaction Processing Systems (TPS): Systems to capture internal (as well as external) data about performance measures to be reported to corresponding managers

2. Management Reporting Systems (MRS): Reporting systems to provide key performance indicators for each manager at all managerial levels and in all functional areas 
3. Decision Support Systems (DSS): Systems to help with root cause analysis, problem solving, planning, and decision making to effect changes to get back on course when a performance measure is not being met

This concise system view of MIS has from time to time been made murky by the hype cycle (O'Leary, 2008) for new systems. It is only the passing of time that lifts the fog of exciting system abbreviations and terminology to show that the new systems are either encompassed in one of the 3 subsystems above or span one or more of them. For example, EIS is a part of MRS, while ESS spans both MRS and DSS. Similarly, KMS is a part of DSS, while ERP spans all 3 types of subsystems.

Today, Big Data (Zikopoulos, et al., 2012) and its hype cycle are presenting IT management with fundamental questions. Does Big Data (that is, the tools and techniques needed to access, organize, and glean discoveries from huge volumes of digital data) change the above system view of MIS? Should the MIS function lead with Big Data projects or follow other functions' lead in Big Data analytics and data science endeavors for the enterprise?

In the following sections we point out that the answers to these questions are existential ones addressing the essence of the mission of the MIS function in the enterprise. Moreover, we argue that Big Data changes everything to the extent that IT management's continued miscalculation on the role of the MIS function can tip the balance of full expectation for IT investments and CIO accountability against it.

\section{THE PLACE OF MIS FUNCTION IN THE ORGANIZATIONAL SYSTEM}

Given that an organization's MIS is the system to support managers of the firm, at all managerial levels and in all functional areas, for their planning and control needs, it is appropriate to consider the place of the MIS subsystem within the larger organizational system. Figure 1 presents a general systems model of the firm (McLeod and Schell, 2007) as a feedback controlled system. Simply stated, any organization, for profit or non-profit, manufacturing or service, can be modeled as a production chain consisting of input, transformation, and output subsystems whose role is to transform raw materials into goods or services. This production chain, however, is controlled through a feedback chain consisting of the goal subsystem, the sensor subsystem whose role is to "sense" how the goal is being met, and the management subsystem whose role is to bring about change to ensure that goals are in fact met.

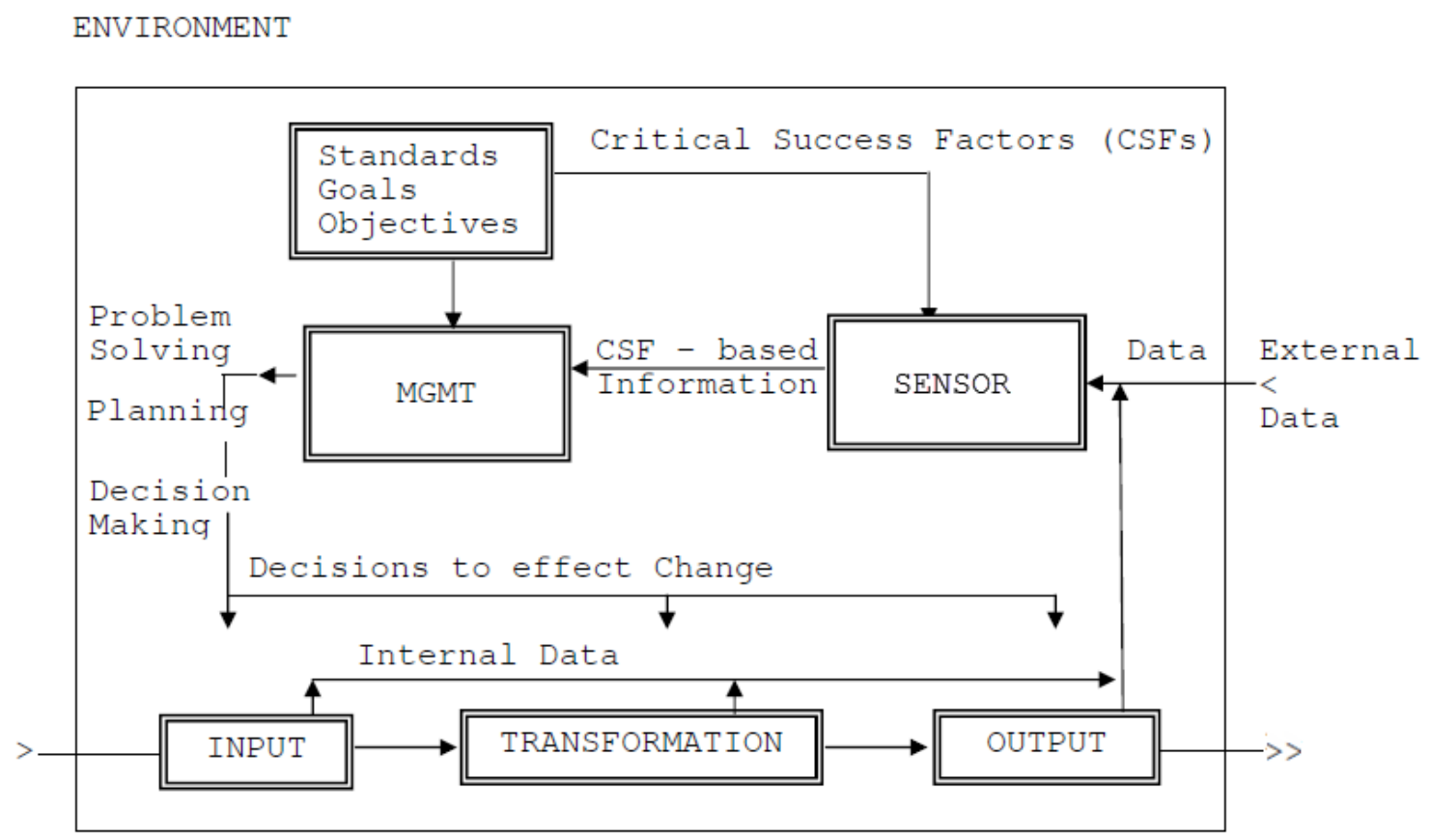

Figure 1. The General Systems Model of the Firm 
It is relatively straightforward to see the place of the MIS function as the sensor subsystem in the general systems model of the firm. A principal role of the MIS function is to collect internal operational data as well as external data about stakeholders in the environment of the firm (i.e., competitors, customers, suppliers, stockholders, financial institutions, regulatory agencies, etc.), to process, filter, and organize that data based on each manager's performance goals (i.e., critical success factors), and to present each manager with the resulting customized Key Performance Indicators (KPIs). Over time, MIS/IT management has excelled in fulfilling this responsibility as illustrated in Figure 2.

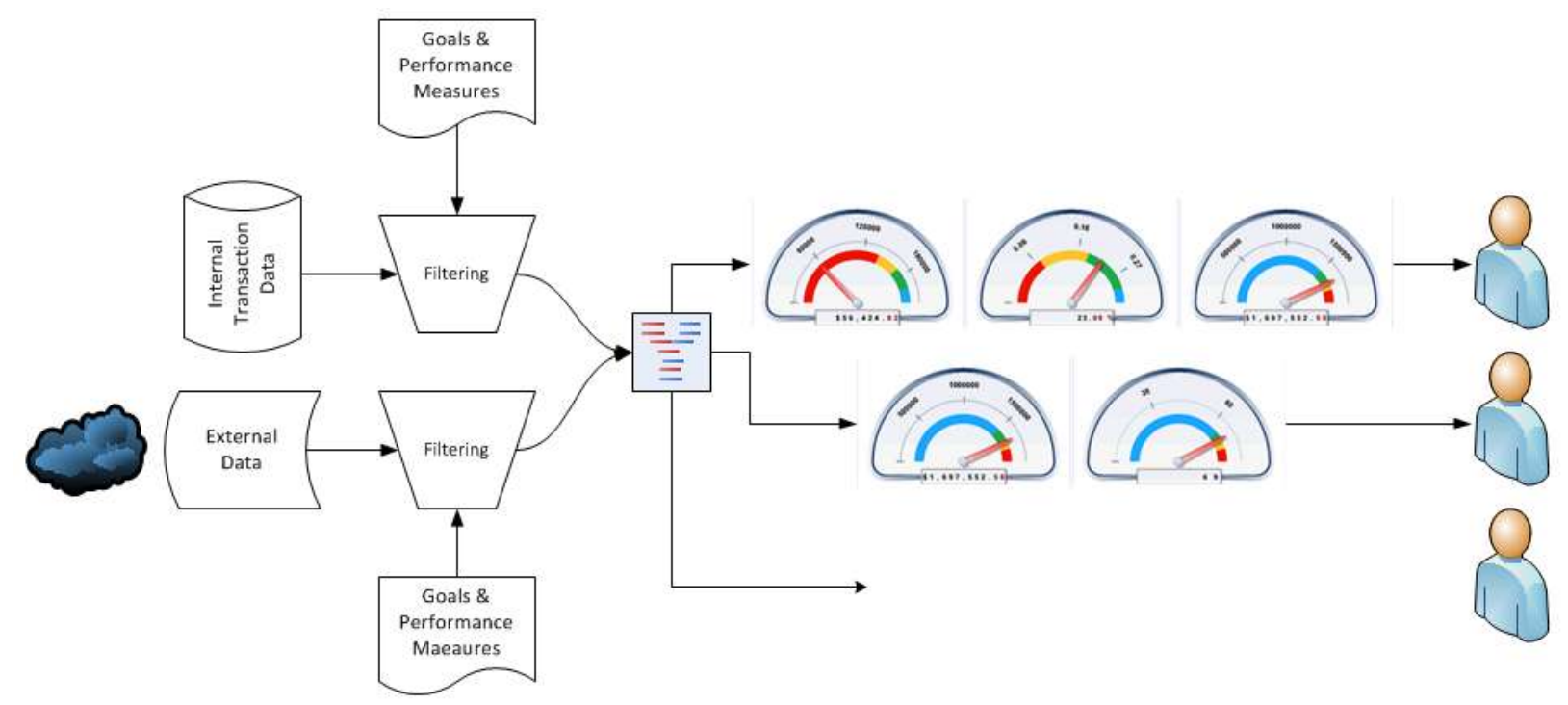

Figure 2. The MIS Function's Support for Management Control and KPIs

In reality, however, much of the emphasis of the MIS function has been focused on KPI's whose measures can be captured as a part of the organization's transaction processing systems including inter-organizational systems. KPI's whose measures require external data such as market share or negative social media buzz about the company are typically labeled as market intelligence and, for the most part, left to be captured by functional areas outside the MIS function. Therein lies the imbalance we observe in most organizations' MIS application portfolio - heavily tilted towards transaction processing systems (TPS) at the expense of decision support systems (DSS).

It is important to acknowledge what amounts to be no less than a herculean effort by IT management to integrate legacy systems and bring about the data and application integration necessary to support managerial control needs, while automating and streamlining business processes and sustaining this effort in light of the rapid technological changes in hardware, software, and communication platforms in a heterogeneous, multi-vendor environment. Nevertheless, continuing to regard the place of the MIS function as a mere substitution for the sensor subsystem in the general systems model of the firm belies the full expectation for IT investments and CIO accountability in organizations. What is long overdue is supporting management, at all managerial levels and in all functional areas, when a KPI gauge goes in the red zone. Then, the MIS support needed is to help identify the root cause, to plan corrective actions, and to make decisions to effect changes that bring back the gauge to its desired mark in the green zone. Figure 3 corrects the general systems model of the form to reflect this DSS-based interaction as a critical secondary output from the MIS subsystem. 


\section{ENVIRONMENT}

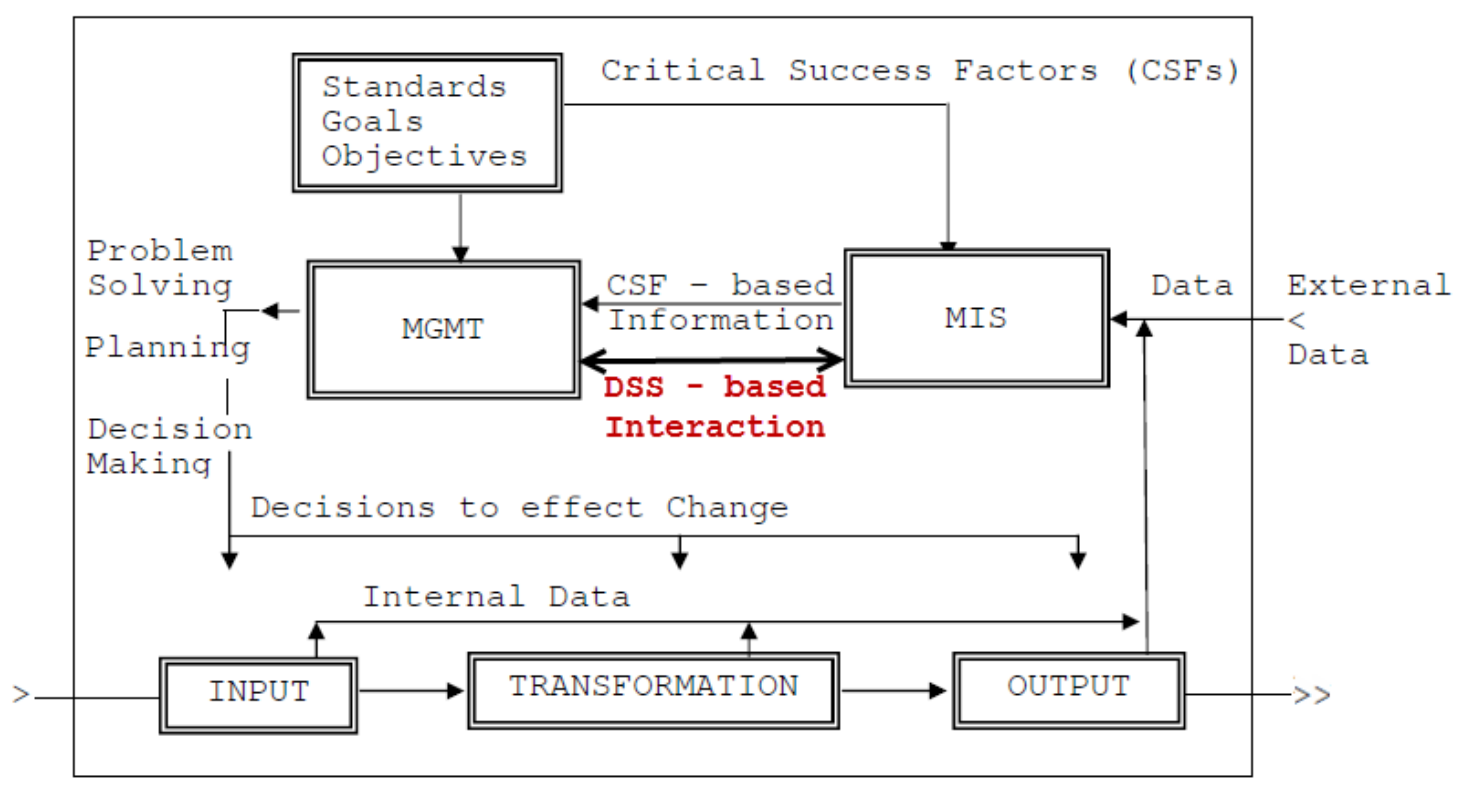

Figure 3. The MIS Subsystem in the General Systems Model of the Firm

\section{THE IMPACT OF BIG DATA ON THE ROLE OF MIS FUNCTION}

Given that the principal outputs of the MIS subsystem are CSF-based reports and DSS-based interaction, how does the advent of Big Data change things? Simply stated, Big Data adds new expectations to the MIS function's role for supporting managerial planning and control. Interestingly, even though Big Data's impact on planning and data-driven decision making is most talked about, it is Big Data's impact on managerial control that rings the wake-up call from complacency for IT management. Figure 4 illustrates this new expectation in a manager's KPI dashboard in the era of Big Data. Decision modeling and prediction will no longer be reactive steps to be taken when a KPI gauge enters the red zone. Instead, predictive analytics must become integral to the MIS function's crowning accomplishment - supporting each manger with his/her dashboard of KPIs - where predicted KPI measures must now appear next to the traditional actual and extrapolated values.

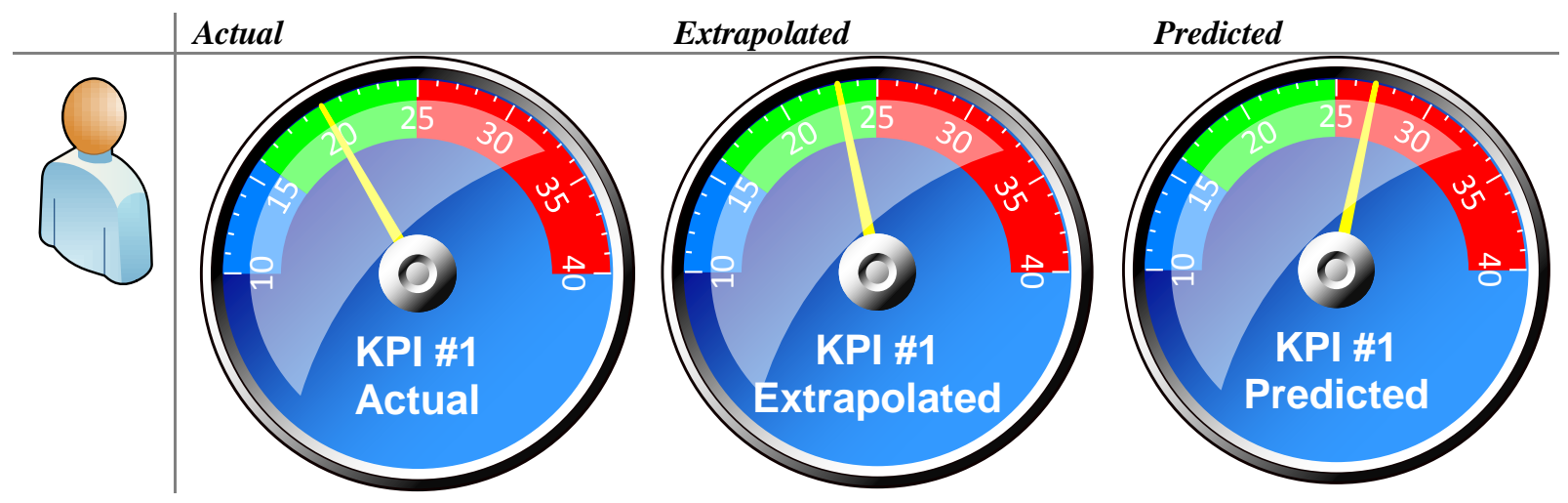

Figure 4. The Big Data/Predictive Analytics Impact on Key Performance Indicator Reporting

Big Data with its open embracement of unstructured data (websites, press releases, newsfeeds, internal documents, e-mails, log files, Tweets, Facebook posts, blog comments, etc.) also increases the expectation from the 
MIS function towards supporting market intelligence. KPIs tied to external data such as market penetration shares, brand identity and loyalty, switching costs, relative price performance with substitutes, access to suppliers and distribution networks, and the many facets of competitive intelligence and customer experience management that have been difficult to measure and report can now become feasible through continued performance improvements in text analytics and natural language processing. The MIS function has no choice but to embrace such technologies just to continue to support managerial control needs.

Once the MIS function accepts its Hobson's choice in relation to assimilating Big Data technologies in support of delivering KPI's, it would be a missed opportunity to remain content to play second fiddle to domain experts, knowledge engineers, and decision modelers from outside the IT function for the same managers' needs for problem solving, planning, and decision making. Figure 5 provides the classic framework (Sprague, 1980) of how different actors participate in building a specific decision support system (DSS). The role of the MIS function in this framework has been that of the technical supporter and tool smith while the DSS builder's role is that of a decision modeler familiar with the problem area and the capabilities of the DSS "generator" platform. It is in large part due to the implicit acceptance of this separation of roles that the MIS function has neither developed the in-house competencies for DSS builder roles nor has taken a leadership role for the DSS component of the MIS portfolio - instead concentrating on the TPS and MRS components. Big Data changes that.

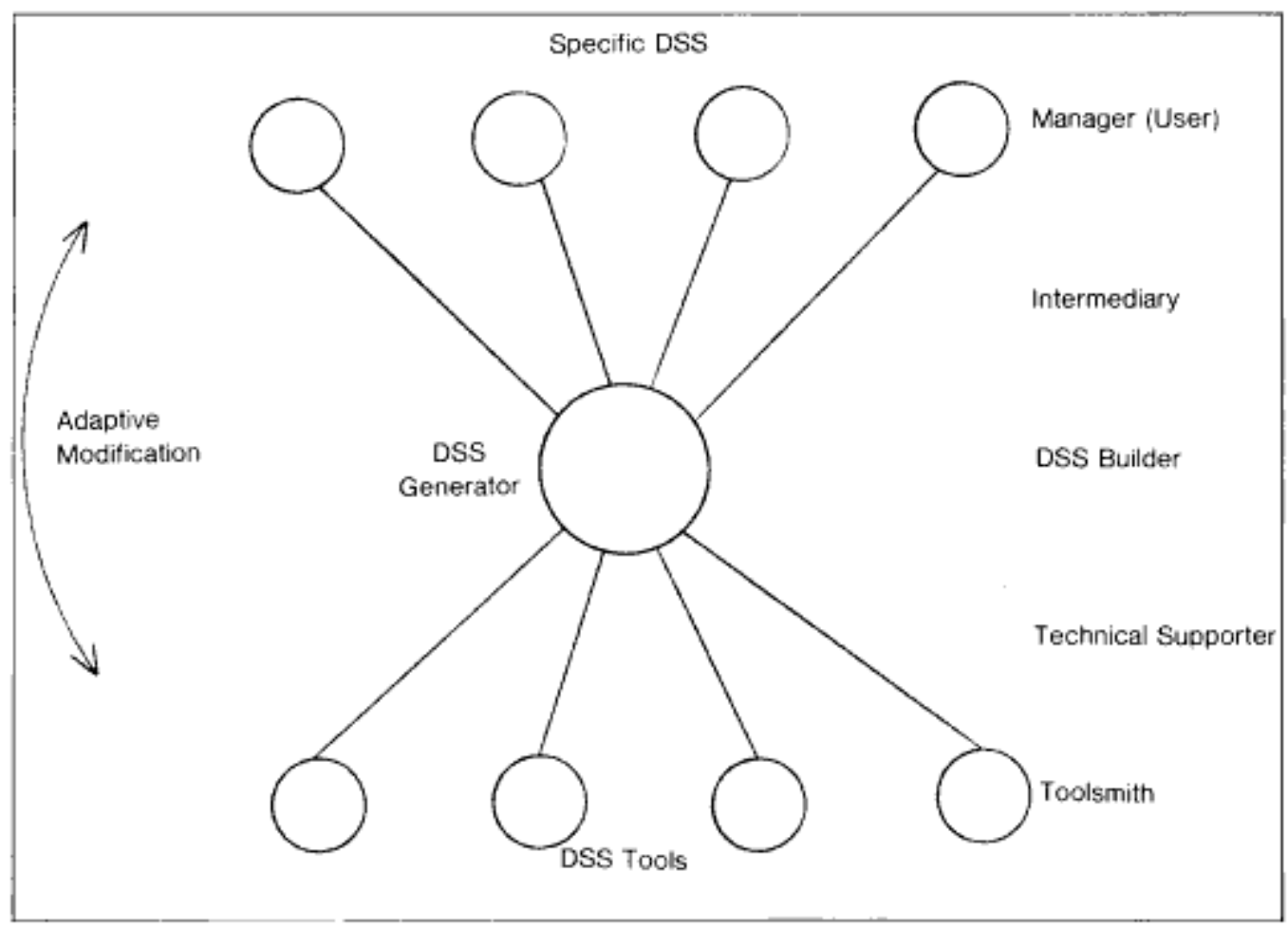

Figure 5. The Classic View of the Role of MIS Function in Building a DSS (Sprague, 1980)

The requirement to bring predictive analytics to KPI reporting combined with the need to process Big Data for KPI's tied to external, market intelligence data mean that the MIS function must develop DSS builder competencies. Today, that means business analytics and data science skills (Patil, 2011). And, once those skills and data science teams are part of the MIS function, it can assume the leadership role in using Big Data to support realtime problem solving, planning, and decision making. 


\section{CONCLUSIONS}

Big Data has all the hallmarks of a technology wave such as the Personal Computer or the World Wide Web which is big enough to spawn new industries that change the world. According to Namee and Maples (2011), a technology wave starts with advances in infrastructure that are the preliminary forces that enable a large wave to gather. This is followed by enabling technologies and platforms that create the foundation for new types of applications. It is finally the applications that cause a gathering wave to achieve massive penetration and customer adoption. In the current Big Data technology wave, pervasive computing in terms of an instrumented and interconnected world - what IBM (2009) refers to as Smarter Planet - created the infrastructure for extremely large volumes of data with extremely wide variety being produced and changed at extremely high velocities. Next, came the enabling technologies, best exemplified by Hadoop (Zikopoulos, et al., 2012), from companies such as Yahoo, Google, and Amazon for storing, parallel processing, and analyzing this avalanche of data. This is now being followed by applications in predictive analytics, text analytics, voice/speech analytics, video analytics that promise actionable insights leading to faster, cheaper, and better data-driven decision making in organizations (McAfee and Brynjolfsson, 2012).

This paper has pointed out that even though Big Data's impact on planning and data-driven decision making is most talked about; it is Big Data's impact on managerial control that rings the wake-up call from complacency for IT management. Specifically, in the era of Big Data, KPI reporting - the crowning achievement of the MIS function in supporting managerial control - must include predictive analytics that employ real-time monitoring of multi-variable decision models to predict missed performance measures. As such, the MIS function has no choice but to embrace Big Data technologies and to develop DSS builder competencies long relegated to outside the MIS function. With decision modeling and data science capabilities at its disposal, the MIS function will be well positioned to successfully surf the Big Data technology wave by providing model-driven, real-time rapid adjustments necessary to help prevent a predicted KPI from in fact entering its red zone.

\section{AUTHOR INFORMATION}

Mohammad Dadashzadeh serves as Professor of MIS and Chair of Department of Decision and Information Sciences and the coordinator of the 1-year, half on-line program leading to a Master of Science in IT Management focusing in Business Analytics from Oakland University. He has authored 4 books and more than 50 articles on information systems and has served as the editor-in-chief of Journal of Database Management. E-mail: dadashza@oakland.edu

\section{REFERENCES}

1. IBM. (2009) Smarter Planet. IBM, 2009, June 13, 2013.

2. McAfee, A. and Brynjolfsson, E. (2012) "Big Data: The Management Revolution," Harvard Business Review, October 2012, pp. 60-68.

3. McLeod, R. and Schell, G. (2007) Management Information Systems, $10^{\text {th }}$ Edition. Prentice Hall, Upper Saddle River: NJ.

4. McNamee, R. and Maples, M. Jr. (2011) “Technology Waves and the Hypernet,” Roger and Mike's Hypernet Blog. N.p., December 22, 2011, June 13, 2013.

5. O'Leary, D.E. (2008) “Gartner's Hype Cycle and Information System Research Issues," International Journal of Accounting Information Systems, Vol. 9, No. 4, pp. 240-252.

6. Patil, D.J. (2011) Building Data Science Team. O'Reilly Media, Sebastopol, CA.

7. Sprague, R.H. Jr. (1980) “A Framework for the Development of Decision Support Systems," MIS Quarterly, Vol. 4, No. 4, pp. 1-26.

8. Zikopoulos, P.C., Eaton, C., deRoos, R., Deutsch, T., and Lapis, G. (2012) Understanding Big Data: Analytics for Enterprise Class Hadoop and Streaming Data. McGraw-Hill, New York, NY. 